\title{
Influence of personality traits in coping skills in individuals with bipolar disorder
}

\section{A influência dos traços de personalidade nas habilidades de coping de indivíduos com transtorno de humor bipolar}

\author{
Érika Leonardo de Souza1, Rodrigo Grassi-Oliveira², Elisa Brietzke33, Breno Sanvicente-VIeira², Ledo Daruy-Filho², \\ RicARdo Alberto MoReno ${ }^{1}$
}

1 Mood Disorders Unit (GRUDA) - Institute and Department of Psychiatry, Medical School, Universidade de São Paulo, São Paulo, SP, Brazil.

2 Developmental Cognitive Neuroscience Research Group, Postgraduate Program in Psychology, Pontifical Catholic University of Rio Grande do Sul, Porto Alegre, RS, Brazil.

3 Program for Recognition and Treatment of Individuals in At-Risk Mental States, Department of Psychiatry, Universidade Federal de São Paulo, São Paulo, SP, Brazil.

Received: 6/24/2014 - Accepted: 7/21/2014

DOI: 10.1590/0101-60830000000019

\begin{abstract}
Background: Bipolar disorder is marked by alterations in coping skills which in turn impacts the disease course. Personality traits are associated with coping skills and for this reason it has been suggested that personality traits of patients with BD may have influence over their coping skills. Objective: To investigate possible associations between coping skills and personality in individuals with bipolar disorder (BD). Methods: Thirty-five euthymic subjects with BD were compared with 40 healthy controls. Coping skills were evaluated using Ways of Coping Checklist Revised and Brief-COPE. Personality traits were assessed by Neo Personality Inventory. MANCOVA was used for between groups comparison. Results: Regarding coping, individuals with BD reported more frequent use of emotion-focused strategies than problem-focused strategies, and high levels of neuroticism and low levels of extroversion and conscientiousness on personality measures. Neuroticism influenced negatively the use of problem-focused strategies, and positively emotion-focused coping. Conscientiousness influenced the use of problem-focused strategies in both groups. There was a significant difference between emotion focused coping and personality traits between BD and control groups. Discussion: Personality traits seem to modulate coping skills and strategies in BD which may be took into account for further interventions.
\end{abstract}

Souza EL, et al. / Rev Psiq Clín. 2014;41(4):95-100

Keywords: Bipolar disorder, coping, stress, personality, psychopathology.

\section{Resumo}

Contexto: O transtorno de humor bipolar (THB) é marcado por estratégias de enfrentamento, ou coping, que determinam comportamentos que podem influenciar negativamente o curso da doença. Traços de personalidade são altamente associados com estratégias de coping, portanto se faz a hipótese de que traços de personalidade influenciem as estratégias de coping de portadores de THB. Objetivo: Este estudo buscou investigar associações entre traços de personalidade e estratégias de coping em pacientes com THB. Métodos: Trinta e cinco participantes eutímicos diagnosticados com THB e 40 controles saudáveis participaram deste estudo. Estratégias de coping foram avaliadas com a Ways of Coping Checklist Revised and Brief - COPE - e traços de personalidade foram avaliados com o Neo Personality Inventory. Resultados: Participantes com THB possuíram padrão de estratégias de coping significativamente mais baseados na emoção. Em termos de traços de personalidade, participantes com THB tiveram significativamente mais características de neuroticismo e reduzidas características de extroversão e consciência. Foram encontradas associações positivas entre índices de neuroticismo e estratégias de coping baseadas em emoções e associações negativas com estratégias baseadas no problema. Conclusão: Traços de personalidade são fundamentais para as estratégias de coping de pacientes com THB, portanto traços de personalidade devem ser considerados alvos terapêuticos para a psicopatologia.

Souza EL, et al. / Rev Psiq Clín. 2014;41(4):95-100

Palavras-chave: Transtorno de humor bipolar, coping, estresse, personalidade, psicopatologia.

\section{Introduction}

Bipolar disorder (BD) is a chronic and potentially severe mood disorder, which affect several domains of life such as work, interpersonal relationships and general health. A body of evidence indicates that psychological stress can play a key role in triggering mood episodes of $\mathrm{BD}$ in vulnerable individuals ${ }^{1,2}$. In addition, during the course of disease, stress influences negatively the course of the disease, contributing for progressive shortening in interespisodic periods, increasing in severity of episodes and treatment resistance ${ }^{3,4}$.

In order to cope with stress, individuals need to use coping strategies - a set of coordinated cognitive and behavioral efforts to deal with internal or external demands, appraised by the individual as an overload or a situation which overwhelms their personal resources 5 . Coping strategies can be focused in different types of behaviors. For example, emotion-focused coping refers to efforts to deal with emotional states associated with stress, through somatic aspects and/ or feelings, like to refuse to believe that something has happened.
In other hand, problem-based coping denotes efforts to act on stressful events with the objective to change them, like to take actions to make the situation better ${ }^{6}$.

Besides using coping strategies to deal with specific events, coping also can be approached as a more tonic way of coping: as a style. According to Carver and Scheier ${ }^{7}$, coping styles are the trend of an individual to react in response to situations of stress. Based on this view, people prefer to adopt a relatively stable repertory of coping strategies over time in different situations. Therefore, the coping style used along the time has been understood as a personality trait ${ }^{7}$.

Independently of its theoretical understanding, coping represents a potential target for psychosocial interventions in $\mathrm{BD}^{8}$. In fact, efficient interventions for BD generally include techniques for problem solving and stress management ${ }^{9,10}$, aspects with belong to coping concept. Personality can modulate exposure to stress and reactivity to stressful events, influencing choice of coping strategies and their efficiency ${ }^{11}$. 
One of the models to personality is the so called Five Factor Model (FFM) ${ }^{12}$. Personality aspects are distributed in five big factors: (1) neuroticism: emotional instability, with a tendency to interpret ordinary situations as threatening, presenting anger, anxiety, depression and vulnerability; (2) openness to experience: preference for novelty and independence, with demonstrations of creativity and intellectual curiosity; (3) conscientiousness: preference for discipline and planning, with few spontaneous behaviors; (4) extraversion: assertiveness and enthusiasm, search for social contact and participation in numerous activities; (5) agreeableness: a generous and friendly behavior, with optimism and social harmony'13.

Investigation of association between coping and personality has been conducted in different populations, both clinical and non-clinical. Connor-Smith and Flachsbart ${ }^{14}$ conducted a metaanalysis and found that personality traits such as high extroversion and conscientiousness predicted greater problem-focused coping and cognitive restructuring. On the other hand, high neuroticism predicted strategies such as fantasy thoughts, neglect and emotionfocused coping.

The aim of this study was to investigate associations between coping skills and personality traits in individuals with BD. Our hypothesis holds that patients with BD have lower mean values for problem-focused coping and higher means for emotion-focused coping than healthy controls, and that these results are associated with specific personality traits.

\section{Methods}

\section{Sample}

A total of 35 (20 type I and 15 type II) euthymic individuals with BD from two outpatients units of the tertiary public health service were selected. Diagnosis of BD was established using the Structured Clinical Interview for DSM-IV for Axis I disorders (SCID-I) ${ }^{15}$. Euthymia was defined as not fulfillment of DSM-IV-TR criteria for depressive and manic/hypomanic episodes and present Young Mania Rating Scale (YMRS) ${ }^{16,17}$ scores $\leq 12$ and Hamilton Depression Rating Scale (HAMD)- 17 items score $\leq 718,19$. Inclusion criteria also include age between 18 and 60 years old and ability to read and understand informed consent. Exclusion criteria were organic mental conditions, dementia, mental retardation and substance abuse or dependence in the previous three months (except nicotine and caffeine).

The control group comprised 40 individuals selected by convenience with no history of current or lifetime psychiatric disorders according to SCID ${ }^{15}$. In addition, only individuals with absence of psychiatric history in first-degree relatives were selected. An interview was done to investigate the familiar history of psychiatric disorders.

All the participants provided written informed consent before their inclusion and the research protocol was approved by the Research Ethics Committees of the respective institutions.

\section{Instruments}

Coping skills were assessed using two instruments. The Ways of Coping Checklist Revised (WCCL-R) ${ }^{20}$ was used to assess coping strategies. WCCL-R is a 45 -item Likert-type questionnaire evaluating thoughts and actions deployed to cope with internal and external demands of a specific stressor event. The validated version for the Brazilian population recognizes four ways of coping ${ }^{21}$ : (1) Problemfocused Coping (e.g. "I find different solutions to my problem"), (2) Emotion-focused Coping (e.g. "I find someone to blame for the situation"), (3) Religious Practices/fantasy thoughts (e.g. "I've been hoping for a miracle"; "I pray"), and (4) Seeking Social Support (e.g. "I've been asking a relative or friend I respect for advice"; "I talk to someone about how I'm feeling").

The Brief COPE 22,23 , was used to assess coping styles. This instrument is composed by 28 items and comprises 14 domains, namely: (1) Active coping: taking action or making efforts to remove or overcome the stressor (e.g. "I've been concentrating my efforts on doing something about the situation I'm in"); (2) Planning: rationalizing about ways to tackle the stressor, planning active coping efforts (e.g. "I've been trying to come up with a strategy about what to do"); (3) Use of instrumental support: seeking help, information or advice on what to do (e.g. "I've been getting help and advice from other people"); (4) Use of social/emotional support: seeking empathy or emotional support from someone (e.g. "I've been getting comfort and understanding from someone"); (5) Religion: increasing participation in religious activities (e.g. "I've been trying to find comfort in my religion or spiritual beliefs"); (6) Positive reframing: making the best of the situation by growing from it, or seeing it in a more positive light (e.g. "I've been looking for something good in what is happening"); (7) Self-blame: blaming or criticizing oneself for what happened (e.g. "I've been blaming myself for things that happened"); (8) Acceptance: accepting the fact a stressing event has taken place and is real (e.g. "I've been refusing to believe that it has happened"); (9) Venting: increasing awareness of personal emotional stress and a concomitant tendency to express or vent these feelings (e.g. "I've been saying things to let my unpleasant feelings escape"); (10) Denial: attempting to reject the reality of the stressing event (e.g. "I've been using alcohol or other drugs to help me get through it"); (11) Self-distraction: mental disengagement from the objective that the stressor is influencing by daydreaming, sleep or self-distraction (e.g. "I've been doing something to think about it less, such as going to movies, watching TV, reading, daydreaming, sleeping, or shopping"); (12) Behavioral disengagement: giving up or no longer striving to reach the goals affected by the stressor (e.g. "I've been giving up trying to deal with it"); (13) Substance use: using alcohol or other drugs, even prescription drugs, as a way of evading the stressor (e.g. "I've been using alcohol or other drugs to help me get through it"); 14) Humor: making jokes about the stressor (e.g. "I've been making fun of the situation"). A Portuguese version of the COPE was used ${ }^{23}$.

For this scale, in line with the authors' recommendations, the fourteen domains were regrouped into three factors: (1) Problem-focused coping: including: a) Active coping; b) Planning; c) Use of Instrumental support; d) Use of social/emotional support; e) Positive reframing; f) Acceptance; (2) Emotion-functional focused coping including: a) Religion; b) Venting; c) Self-distraction; d) Humor; and (3) Emotion-dysfunctional focused coping including: a) Self-blame; b) Denial; c) Behavioral disengagement; d) Substance use. To verify if this theoretical grouping was in accordance with the data, an exploratory factorial analysis was performed. The three factors demonstrated good levels of internal consistency ( $\alpha=0.75$, 0.68 and 0.74 , respectively).

The Revised NEO Personality Inventory (NEO-PI-R)24,25 was used to assess personality traits. This instrument is based on five major latent factors, or domains, each of which has six facets, involved in people's responses: Neuroticism (Anxiety, Angry Hostility, Depression, Self-Consciousness, Impulsiveness, Vulnerability); Extraversion (Warmth, Gregariousness, Assertiveness, Activity, ExcitementSeeking, Positive Emotions); Openness (Fantasy, Aesthetics, Feelings, Actions, Ideas, Values); Agreeableness (Trust, Straightforwardness, Altruism, Compliance, Modesty, Tender-Mindedness) and; Conscientiousness (Competence, Order, Dutifulness, Achievement Striving, Self-Discipline, Deliberation).

\section{Statistical analysis}

Data were tabulated and analyzed using SPSS v.20.0. Comparisons between the groups of cases and controls were conducted using Student's $t$ test and the Chi-squared test when appropriated. The critical value for statistical significance was set at an alpha level $<.05$. Comparison between groups in coping and personality scales were performed using multivariate analysis of co-variance (MANCOVA), introducing age and sex as co-variables. Associations between coping and personality were determined by multiple linear regressions. Constructed models included coping strategies and styles as dependent variables and personality traits that differed statistically between 
groups as independent variables. Regression analyses were controlled for gender and age, and performed using the Forward method.

In order to determine the potential influence of facets of personality on coping strategies and styles, an analysis of multiple linear regression including only patients with BD was performed, with the inclusion of those facets of personality traits associated with coping strategies and styles. Regression analyses were controlled for gender and age, and performed using the Forward method.

\section{Results}

\section{Sample characterization}

Clinical and demographic characteristics of the sample are described in table 1. Significant differences were found for both age and sex, with patients with $\mathrm{BD}$ being older than healthy controls, and the bipolar group contained a higher proportion of women compared to the control group.

Differences in coping skills and personality traits between the groups

Comparison between the groups (Table 2) revealed that patients with $\mathrm{BD}$ reported more frequent use of emotion-focused coping strategies $(\mathrm{p}<0.001)$ and less frequent use of problem-focused strategies (WCCL-R). A similar result was evident for coping styles on the Brief COPE scale, which showed that individuals with $\mathrm{BD}$ made less frequent use of problem-focused coping and greater use of emotion-focused coping for both functional and dysfunctional types.

On personality measures, individuals with $\mathrm{BD}$ exhibited higher Neuroticism, lower Extraversion and lower Conscientiousness scores compared to the control group (Table 3). In addition, individuals with $\mathrm{BD}$ had higher mean scores on all facets of Neuroticism than controls. For the Extraversion trait, patients had lower scores on Warmth, Gregariousness and Activity. Similarly, for Conscien- tiousness, patients with BD scored lower on the facets Competence, Order, Achievement Striving, Self-Discipline and Deliberation, compared to controls.

\section{Associations between coping and personality}

In order to detect differences in the influence of traits as Neuroticism, Extraversion and Conscientiousness on coping strategies and styles among patients with $\mathrm{BD}$ and healthy controls, it was investigated by a multiple linear regression model comprising factors from the coping scales (dependent variables) and personality factors (independent variables). The regression equations are depicted in table 4 .

The results showed that Neuroticism influenced the use of problem-focused strategies (WCCL-R) and the trait Conscientiousness influenced the use of problem-focused strategies in both BD and healthy control groups. Regarding emotion-focused coping (WCCL-R), it was found affected for by Neuroticism in both groups. Similarly, problem-focused coping (Brief COPE) was affected by Conscientiousness in both groups. Emotion-dysfunctional focused coping (Brief COPE) was impacted by Extraversion in the bipolar group and by Neuroticism in the control group.

Regression coefficients were compared in order to determine whether relationships between personality trait and coping differed between bipolar and control groups. Comparison of regression coefficients yielded significant differences only for emotion-focused coping (WCCL-R) $(\mathrm{p}=0.018)$.

When only the group of $\mathrm{BD}$ patients was examined, the depression facet (Neuroticism) exerted an influence on the use of problemfocused coping strategies (WCCL-R) (Table 5). Emotion-focused coping (WCCL-R) was influenced for by the Impulsiveness and Anxiety (Neuroticism). On the analysis of coping styles, the SelfDiscipline facet (Conscientiousness) influenced problem-focused coping, while the Assertiveness facet (Extraversion) influenced emotion-focused coping.

Table 1. Clinical and demographic characteristics of the sample

\begin{tabular}{|l|c|c|c|}
\hline Variable & BD & HC & p-value \\
\hline Age in years (mean, SD) & $42.91( \pm 13.83)$ & $33.63( \pm 10.98)$ & $0.002^{\mathrm{a}}$ \\
\hline Years of Education (mean, SD) & $11.29( \pm 4.32)$ & $12.72( \pm 2.75)$ & $0.071^{\mathrm{a}}$ \\
\hline Sex & & & $0.007^{\mathrm{b}}$ \\
\hline Men (N/\%) & $7(20 \%)$ & $20(50 \%)$ & \\
\hline Women (N/\%) & $28(80 \%)$ & $20(50 \%)$ & $<0.001^{\mathrm{a}}$ \\
\hline Total HAM-D Score (mean, SD) & $4.00( \pm 2.46)$ & $0.17( \pm 0.38)$ & $<0.001^{\mathrm{a}}$ \\
\hline Total YMRS Score (mean, SD) & $2.40( \pm 2.0)$ & $0.17( \pm 0.38)$ & \\
\hline
\end{tabular}

a: Student's t test; b: chi-square test; BD: bipolar disorder; $\mathrm{HC}$ : health controls.

Table 2. Comparison of coping measures between the groups

\begin{tabular}{|c|c|c|c|c|c|}
\hline & $\begin{array}{c}\text { BD } \\
\text { Mean (SD) }\end{array}$ & $\begin{array}{c}\mathrm{HC} \\
\text { Mean (SD) }\end{array}$ & $\mathrm{F}$ & Eta $^{2}$ & Power \\
\hline \multicolumn{6}{|l|}{ WCCL-R } \\
\hline Problem-focused coping** & $3.18( \pm 0.54)$ & $3.77( \pm 0.43)$ & 25.47 & 0.26 & 0.999 \\
\hline Emotion-focused coping ${ }^{* *}$ & $2.82( \pm 0.80)$ & $2.01( \pm 0.46)$ & 28.59 & 0.28 & 1.00 \\
\hline $\begin{array}{l}\text { Religious practices/fantasy } \\
\text { thoughts }\end{array}$ & $3.37( \pm 0.86)$ & $2.67( \pm 0.88)$ & 3.61 & 0.04 & 0.46 \\
\hline Seeking social support & $3.04( \pm 0.67)$ & $3.11( \pm 0.60)$ & 0.16 & 0.00 & 0.06 \\
\hline \multicolumn{6}{|l|}{ Brief COPE } \\
\hline Problem-focused COPING* & $1.77( \pm 0.41)$ & $1.96( \pm 0.47)$ & 4.97 & 0.06 & 0.59 \\
\hline $\begin{array}{l}\text { Emotion-functional focused } \\
\text { coping }^{*}\end{array}$ & $1.75( \pm 0.50)$ & $1.35( \pm 0.45)$ & 4.44 & 0.005 & 0.54 \\
\hline $\begin{array}{l}\text { Emotion-dysfunctional } \\
\text { focused coping }\end{array}$ & $0.95( \pm 0.52)$ & $0.42( \pm 0.29)$ & 21.19 & 0.23 & 0.99 \\
\hline
\end{tabular}

${ }^{*} p<0.05 ;{ }^{*} p<0.001$; WCCL-R: Ways of Coping Revised; BD: bipolar disorder; HC: health controls. 
Table 3. Comparison of personality traits and their facets between the two groups

\begin{tabular}{|c|c|c|c|c|c|c|}
\hline & $\begin{array}{c}\mathrm{BD} \\
\text { Mean }(\mathrm{SD})(\mathrm{N}=35)\end{array}$ & $\begin{array}{c}H C \\
\text { Mean }(S D)(N=40)\end{array}$ & $\mathrm{F}$ & $p$-value & Effect size & Power \\
\hline Neuroticism & $111.71( \pm 20.13)$ & $78.50( \pm 22.39)$ & 46.30 & $<0.001$ & 0.395 & 1.000 \\
\hline N1: Anxiety & $18.60( \pm 3.38)$ & $14.75( \pm 3.40)$ & 23.01 & $<0.001$ & 0.245 & 0.997 \\
\hline N2: Angry hostility & $17.74( \pm 5.79)$ & $12.40( \pm 5.12)$ & 16.17 & $<0.001$ & 0.186 & 0.978 \\
\hline N3: Depression & $20.74( \pm 5.17)$ & $12.15( \pm 5.26)$ & 47.71 & $<0.001$ & 0.402 & 1.000 \\
\hline N4: Self-Consciousness & $19.17( \pm 3.68)$ & $14.90( \pm 5.21)$ & 21.80 & $<0.001$ & 0.235 & 0.996 \\
\hline N5: Impulsiveness & $18.34( \pm 5.48)$ & $14.02( \pm 4.44)$ & 20.66 & $<0.001$ & 0.225 & 0.994 \\
\hline N6: Vulnerability & $17.11( \pm 5.73)$ & $10.27( \pm 4.20)$ & 26.22 & $<0.001$ & 0.270 & 0.999 \\
\hline Extraversion & $96.28( \pm 24.46)$ & $117.15( \pm 16.57)$ & 10.57 & 0.002 & 0.130 & 0.894 \\
\hline E1: Warmth & $19.62( \pm 6.06)$ & $23.25( \pm 3.31)$ & 8.29 & 0.005 & 0.105 & 0.811 \\
\hline E2: Gregariousness & $13.42( \pm 5.90)$ & $18.45( \pm 3.31)$ & 14.53 & $<0.001$ & 0.170 & 0.964 \\
\hline E3: Assertiveness & $14.08( \pm 4.84)$ & $17.00( \pm 4.39)$ & 3.87 & 0.053 & 0.052 & 0.493 \\
\hline E4: Activity & $15.25( \pm 4.65)$ & $17.75( \pm 3.53)$ & 3.39 & 0.070 & 0.046 & 0.444 \\
\hline E5: Excitement-Seeking & $17.20( \pm 5.39)$ & $19.42( \pm 3.84)$ & 0.35 & 0.554 & 0.005 & 0.090 \\
\hline E6: Positive emotions & $16.68( \pm 5.90)$ & $21.27( \pm 4.91)$ & 7.34 & 0.008 & 0.094 & 0.762 \\
\hline Openness & $101.97( \pm 19.05)$ & $111.25( \pm 13.86)$ & 2.00 & 0.162 & 0.027 & 0.287 \\
\hline 01: Fantasy & $17.57( \pm 5.73)$ & $17.40( \pm 4.00)$ & 1.10 & 0.297 & 0.015 & 0.179 \\
\hline 02: Aesthetics & $18.97( \pm 3.75)$ & $17.75( \pm 3.99)$ & 0.61 & 0.435 & 0.009 & 0.121 \\
\hline 03: Feelings & $17.34( \pm 4.24)$ & $19.12( \pm 3.32)$ & 0.50 & 0.478 & 0.007 & 0.108 \\
\hline 04: Actions & $13.60( \pm 3.06)$ & $16.05( \pm 3.66)$ & 10.44 & 0.002 & 0.128 & 0.890 \\
\hline 05: Ideas & $17.08( \pm 5.35)$ & $20.45( \pm 3.69)$ & 3.92 & 0.052 & 0.052 & 0.497 \\
\hline 06: Values & $17.40( \pm 4.37)$ & $20.47( \pm 2.95)$ & 6.03 & 0.016 & 0.078 & 0.678 \\
\hline Agreeableness & $116.71( \pm 18.24)$ & $115.07( \pm 16.61)$ & 0.85 & 0.358 & 0.012 & 0.150 \\
\hline A1: Trust & $18.00( \pm 5.16)$ & $18.40( \pm 5.27)$ & 0.79 & 0.376 & 0.011 & 0.142 \\
\hline A2: Straightforwardness & $17.74( \pm 5.69)$ & $17.50( \pm 4.54)$ & 2.16 & 0.146 & 0.030 & 0.306 \\
\hline A3: Altruism & $22.65( \pm 5.02)$ & $22.97( \pm 2.82)$ & 0.002 & 0.892 & 0.000 & 0.052 \\
\hline A4: Compliance & $16.57( \pm 4.80)$ & $18.10( \pm 4.81)$ & 4.55 & 0.036 & 0.060 & 0.558 \\
\hline A5: Modesty & $19.48( \pm 3.81)$ & $16.70( \pm 4.15)$ & 3.33 & 0.072 & 0.045 & 0.437 \\
\hline A6: Tender-Mindedness & $22.25( \pm 3.56)$ & $21.40( \pm 2.88)$ & 0.00 & 0.966 & 0.000 & 0.050 \\
\hline Conscientiousness & $103.71( \pm 20.34)$ & $124.30( \pm 17.54)$ & 20.64 & $<0.001$ & 0.225 & 0.994 \\
\hline C1: Competence & $18.74( \pm 4.29)$ & $21.97( \pm 3.10)$ & 13.11 & 0.001 & 0.156 & 0.946 \\
\hline C2: Order & $16.31( \pm 4.78)$ & $18.77( \pm 4.35)$ & 6.04 & 0.016 & 0.078 & 0.679 \\
\hline C3: Dutifulness & $21.51( \pm 5.02)$ & $22.70( \pm 3.82)$ & 3.81 & 0.055 & 0.051 & 0.487 \\
\hline C4: Achievement Striving & $17.97( \pm 4.63)$ & $21.07( \pm 3.41)$ & 5.27 & 0.025 & 0.069 & 0.620 \\
\hline C5: Self-discipline & $13.94( \pm 5.43)$ & $20.65( \pm 4.45)$ & 32.28 & $<0.001$ & 0.313 & 1.000 \\
\hline C6: Deliberation & $15.22( \pm 6.06)$ & $19.12( \pm 5.26)$ & 8.01 & 0.006 & 0.101 & 0.797 \\
\hline
\end{tabular}

BD: bipolar disorder; $\mathrm{HC}$ : health controls.

Table 4. Models of multiple linear regression between coping and personality traits in bipolar and control subjects

\begin{tabular}{|c|c|c|c|c|c|c|}
\hline & $\mathrm{R}$ & $\Delta \mathrm{R}^{2}$ & $\Delta \mathrm{F}$ & df & $\beta$ & $\mathrm{p}$-value \\
\hline \multicolumn{7}{|c|}{ Problem-focused Coping (WCCL-R) } \\
\hline Bipolar & 0.46 & 0.21 & 9.06 & 1.33 & & 0.005 \\
\hline Neuroticism & & & & & -0.46 & 0.005 \\
\hline Control & 0.55 & 0.07 & 4.15 & 1.37 & & 0.049 \\
\hline Neuroticism & & & & & -0.30 & 0.049 \\
\hline Conscientiousness & & & & & 0.36 & 0.020 \\
\hline \multicolumn{7}{|c|}{ Emotion-focused Coping (WCCL-R) } \\
\hline Bipolar & 0.62 & 0.39 & 21.36 & 1.33 & & $<0.001$ \\
\hline Neuroticism & & & & & 0.62 & $<0.001$ \\
\hline Control & 0.53 & 0.28 & 15.37 & 1.38 & & $<0.001$ \\
\hline Neuroticism & & & & & 0.53 & $<0.001$ \\
\hline \multicolumn{7}{|c|}{ Problem-focused Coping (Brief COPE) } \\
\hline Bipolar & 0.46 & 0.21 & 9.11 & 1.33 & & 0.005 \\
\hline Conscientiousness & & & & & 0.46 & 0.005 \\
\hline Control & 0.36 & 0.13 & 5.98 & 1.38 & & 0.019 \\
\hline Conscientiousness & & & & & 0.36 & 0.019 \\
\hline \multicolumn{7}{|c|}{$\begin{array}{l}\text { Emotion-dysfunctional focused } \\
\text { Coping (Brief COPE) }\end{array}$} \\
\hline Bipolar & 0.41 & 0.16 & 6.72 & 1.33 & & 0.014 \\
\hline Extraversion & & & & & -0.41 & 0.014 \\
\hline Control & 0.40 & 0.16 & 7.39 & 1.38 & & 0.010 \\
\hline Neuroticism & & & & & 0.40 & 0.010 \\
\hline
\end{tabular}

WCCL-R: Ways of Coping Revised. 
Table 5. Models of multiple linear regression between coping and personality traits in bipolar group

\begin{tabular}{|l|c|c|c|c|c|c|}
\hline & $\mathrm{R}$ & $\Delta \mathrm{R}^{2}$ & $\Delta \mathrm{F}$ & $\mathrm{df}$ & $\beta$ & $\mathrm{p}$ \\
\hline $\begin{array}{l}\text { Problem-focused Coping } \\
\text { (WCCL-R) }\end{array}$ & 0.44 & 0.19 & 8.12 & 1.33 & & 0.007 \\
\hline Depression 1 & & & & & -0.44 & 0.007 \\
\hline $\begin{array}{l}\text { Emotion-focused coping } \\
\text { (WCCL-R) }\end{array}$ & 0.71 & 0.16 & 10.35 & 1.32 & & \\
\hline Impulsiveness & & & & & 0.48 & 0.001 \\
\hline Anxiety & & & & & 0.41 & 0.003 \\
\hline $\begin{array}{l}\text { Problem-focused Coping } \\
\text { (Brief COPE) }\end{array}$ & 0.44 & 0.19 & 8.06 & 1.33 & & 0.008 \\
\hline Self-Discipline 2 & & & & & 0.44 & 0.008 \\
\hline $\begin{array}{l}\text { Emotion-dysfunctional } \\
\text { focused coping } \\
\text { (Brief COPE) }\end{array}$ & 0.34 & 0.12 & 4.47 & 1.33 & & 0.42 \\
\hline Assertiveness $^{3}$ & & & & & -0.34 & 0.42 \\
\hline
\end{tabular}

1: Facets of neuroticism; 2: Facets of conscientiousness; 3: Facets of extraversion; WCCL-R: Ways of Coping Revised.

\section{Discussion}

The results of this study suggest that individuals with $\mathrm{BD}$ use more frequently emotion-focused strategies than problem-focused strategies, and exhibited higher levels of Neuroticism and lower levels of Extroversion and Conscientiousness when compared to healthy controls. We observed a positive association between Neuroticism and emotion-focused coping, and a negative association between Neuroticism and problem-focused coping. Regarding coping styles, a positive association was identified between problem-focused coping and Conscientiousness, while negative associations were found between Extroversion and problem-focused coping.

High Neuroticism and the choice for emotion-focused coping seem to have similar behavior outcomes, showing anger, anxiety and others unpleasant emotions. This seems to be true also for the concepts of Conscientiousness (a high sense of planning and organization) and a coping based in problem solving. More than this, patients with BD seem to have some difficulty in choosing a form of coping based on problems solving, more adaptive, when they have high levels of Neuroticism and Extroversion (more emotional and energetic personality traits).

These results are in line with a considerable number of previous studies that have described patients with BD to have higher levels of Neuroticism 26-30, lower levels of Extraversion27,30,31, and lower Conscientiousness 26,32 .

Our results also revealed a more emotional coping style, with behaviors and thoughts that can be deemed functional (religiousness, venting of feelings, self-distraction and humor) or dysfunctional (self-blaming, denial, behavioral disengagement, substance use). Although sometimes considered functional, this emotional way of addressing the problem does not seek to act on the situation which gave rise to the stress by attempting to change it (problem-focused coping) but instead aims to govern the emotional state associated with stress, attenuating its detrimental effects ${ }^{33}$. Research has shown that emotion-focused strategies are less effective at reducing emotional stress compared with problem-focused responses ${ }^{34,35}$. Previous studies suggested that patients with BD rely more on emotion-focused strategies that can be linked to recurrence of the disorder ${ }^{36,37}$.

The results of this study must be interpreted at light of its limitations. First, the sample was comprised by patients seen at tertiary public health services, an indicative of the high severity of the disease of these patients, which could be not representative of the population of individuals with BD. By the same token, the sample with BD was heterogeneous regarding the diagnosis of type I and type II BD. It is a limitation since BD type I and II can have different neurocognitive impairments ${ }^{38}$. In addition, limitations exist concerning the self-reported questionnaires, specifically regarding the need for more consistent psychometric data on the Brief COPE. Finally, it is necessary to resemble that our results cannot be interpreted such as robust evidences because we had a small sample size.

Based on our data, it can be concluded that the associations between personality and coping exist and might be relevant to increase our understanding on how this patients react and manage vital events. It is opportune to revisit the concept of coping introduced by Lazarus and Folkman', who defined coping as a group of deliberate actions which are cogitated or carried out in order to deal with a situation, and that can be learned, deployed or rejected. If coping is a dynamic process, there is a possibility to change. However, clinical observation shows that patients are not always successful in learning these strategies, since, as we demonstrate in this study, other factors can influence this learning, such as personality traits. Understanding the complex interactions between these two factors in BD can further increase our knowledge on potential targets for psychosocial interventions and construct, with the patients, a more functional way to respond to stressing vital events, breaking the stress - relapse cycle.

\section{Acknowledgements}

We would like to thank the research funding body Fapesp (Fundação de Amparo à Pesquisa do Estado de São Paulo) for the financial support provided for this study (grant no 2008/04957-0).

\section{Disclosures}

Érika Leonardo de Souza, Rodrigo Grassi-Oliveira, Breno SanvicenteVieira, and Ledo Daruy-Filho: none.

Ricardo Alberto Moreno: Dr. Moreno has acted as a consultant to, and conducted research sponsored by, companies with developments in the area of bipolar and depressive disorders (Servier, BMS, Eli Lilly, Abbott, AstraZeneca, GSK).

Elisa Brietzke: Dr. Brietzke received honoraria as speaker from Janssen-Cilag, Pfizer and Lundbeck.

\section{References}

1. Post R, Leverich G. The role of psychosocial stress in the onset and progression of bipolar disorder and its comorbidities: the need for earlier and alternative modes of therapeutic intervention. Dev Psychopathol. 2006;18(4):1181-211.

2. Proudfoot J, Whitton A, Parker G, Doran J, Manicavasagar V, Delmas K. Triggers of mania and depression in young adults with bipolar disorder. J Affect Disord. 2012;143(1-3):196-202.

3. Brietzke E, Mansur RB, Soczynska J, Powell AM, McIntyre RS. A theoretical framework informing research about the role of stress in the pathophysiology of bipolar disorder. Prog Neuropsychopharmacol Biol Psychiatry. 2012;39(1):1-8.

4. Yan-Meier L, Eberhart NK, Hammen CL, Gitlin M, Sokolski K, Altshuler L. Stressful life events predict delayed functional recovery following treatment for mania in bipolar disorder. Psychiatry Res. 2011;186(2-3):267-71.

5. Lazarus RS. Stress and coping as factors in health and illness. In: Cohen J, editor. Psychosocial aspects of cancer. New York: Raven Press; 1982.

6. Lazarus RS, Folkman S. Stress, appraisal, and coping. New York: Springer Pub. Co.; 1984. xiii, 445 p.

7. Carver CS, Scheier MF, Weintraub JK. Assessing coping strategies: a theoretically based approach. J Pers Soc Psychol. 1989;56(2):267-83.

8. Grassi-Oliveira R, Daruy-Filho L, Brietzke E. New perspectives on coping in bipolar disorder. Psychol Neurosci. 2010;3(2):161-5.

9. Scott J, Colom F, Vieta E. A meta-analysis of relapse rates with adjunctive psychological therapies compared to usual psychiatric treatment for bipolar disorders. Int J Neuropsychopharmacol. 2007;10(1):123-9.

10. Reinares M, Sánchez-Moreno J, Fountoulakis KN. Psychosocial interventions in bipolar disorder: What, for whom, and when. J Affect Disord. 2014;156:46-55.

11. Bolger N, Zuckerman A. A framework for studying personality in the stress process. J Pers Soc Psychol. 1995;69(5):890-902.

12. Tupes EC, Christal RE. Recurrent personality factors based on trait ratings. J Pers. 1992;60(2):225-51. 
13. Digman JM. Personality structure: emergence of the five-factor model. Annu Rev Psychol. 1990;41:417-40.

14. Connor-Smith JK, Flachsbart C. Relations between personality and coping: a meta-analysis. J Pers Soc Psychol. 2007;93(6):1080-107.

15. First MB. Structured clinical interview for DSM-IV axis I disorders: SCID-I: clinician version: administration booklet. Washington, DC: American Psychiatric Press; 1997.

16. Young RC, Biggs JT, Ziegler VE, Meyer DA. A rating scale for mania: reliability, validity and sensitivity. Br J Psychiatry. 1978;133:429-35.

17. Vilela JA, Crippa JA, Del-Ben CM, Loureiro SR. Reliability and validity of a Portuguese version of the Young Mania Rating Scale. Braz J Med Biol Res. 2005;38(9):1429-39.

18. Hamilton M. A rating scale for depression. J Neurol Neurosurg Psychiatry. 1960;23:56-62.

19. Moreno RA, Moreno DH. Escalas de Avaliação para Depressão de Hamilton (HAM-D) e Montgomery Asberg (MADRS). In: Gorenstein C, Andrade L, Zuardi A, editors. Escalas de avaliação clínica em psiquiatria e psicoframacologia. São Paulo: Lemos Editorial; 2000. p. 71-87.

20. Vitaliano PP, Russo J, Carr JE, Maiuro RD, Becker J. The ways of coping checklist: revision and psychometric properties. Multivariate Behavioral Research. 1985;20(1):3-26.

21. Seidl EMF, Tróccoli BT, Zannon CMLC. Factorial analysis of a coping measure. Psic: Teor e Pesq. 2001;17(3):225-34.

22. Carver CS. You want to measure coping but your protocol's too long: consider the brief COPE. Int J Behav Med. 1997;4(1):92-100.

23. Ribeiro JLP, Rodrigues AP. Questões acerca do coping: a propósito do estudo de adaptação do Brief COPE. Psic Saúde Doenças. 2004;5(1):3-15.

24. Costa PT, Fagan PJ, Piedmont RL, Ponticas Y, Wise TN. The five-factor model of personality and sexual functioning in outpatient men and women. Psychiatr Med. 1992;10(2):199-215.

25. Flores-Mendoza CE, Primi R, Nascimento E, Nunes CH. NEO-PI-R Inventário de Personalidade NEO Revisado e Inventário de Cinco Fatores. São Paulo, Brasil: Vetor Editora; 2007.

26. Nowakowska C, Strong CM, Santosa CM, Wang PW, Ketter TA. Temperamental commonalities and differences in euthymic mood disorder patients, creative controls, and healthy controls. J Affect Disord. 2005;85(1-2):207-15
27. Smillie LD, Bhairo Y, Gray J, Gunasinghe C, Elkin A, McGuffin P, et al Personality and the bipolar spectrum: normative and classification data for the Eysenck Personality Questionnaire-Revised. Compr Psychiatry. 2009;50(1):48-53.

28. Jylhä P, Ketokivi M, Mantere O, Melartin T, Suominen K, Vuorilehto M, et al. Temperament, character and personality disorders. Eur Psychiatry. 2013;28(8):483-91.

29. Jylhä P, Mantere O, Melartin T, Suominen K, Vuorilehto M, Arvilommi $\mathrm{P}$, et al. Differences in temperament and character dimensions in patients with bipolar I or II or major depressive disorder and general population subjects. Psychol Med. 2011;41(8):1579-91.

30. Kim B, Lim JH, Kim SY, Joo YH. Comparative study of personality traits in patients with bipolar I and II disorder from the five-factor model perspective. Psychiatry Investig. 2012;9(4):347-53.

31. Jylhä $P$, Mantere $O$, Melartin T, Suominen K, Vuorilehto M, Arvilommi $P$, et al. Differences in neuroticism and extraversion between patients with bipolar I or II and general population subjects or major depressive disorder patients. J Affect Disord. 2010;125(1-3):42-52.

32. Barnett JH, Huang J, Perlis RH, Young MM, Rosenbaum JF, Nierenberg AA, et al. Personality and bipolar disorder: dissecting state and trait associations between mood and personality. Psychol Med. 2011;41(8):1593604.

33. Lazarus RS. Emotions and interpersonal relationships: toward a person-centered conceptualization of emotions and coping. J Pers. 2006;74(1):946.

34. Cruzado JA, Elvira de la Morena MJ. Coping and distress in caregivers of patients with disorders of consciousness. Brain Inj. 2013;27(7-8):793-8.

35. Lee H, Schepp KG. Ways of coping in adolescents with schizophrenia. J Psychiatr Ment Health Nurs. 2011;18(2):158-65.

36. Lam D, Wong G, Sham P. Prodromes, coping strategies and course of illness in bipolar affective disorder - a naturalistic study. Psychol Med. 2001;31(8):1397-402.

37. Greenhouse WJ, Meyer B, Johnson SL. Coping and medication adherence in bipolar disorder. J Affect Disord. 2000;59(3):237-41.

38. Lewandowska A, Rybakowski J. [Neuropsychological aspects of the manic syndrome in the course of bipolar affective illness]. Psychiatr Pol. 2009;43(3):275-86. 